\title{
A Nutritional Evaluation of Vitamin E Status in Very Low Birth Weight Infants with Respect to Changes in Plasma and Red Blood Cell Tocopherol Levels
}

\author{
Hirohisa TANAKA, Makoto MINO ${ }^{1}$ and Tohru TAKEUCHI ${ }^{2}$ \\ ${ }^{1}$ Department of Pediatrics, Osaka Medical College, \\ Takatsuki 569, Japan \\ ${ }^{2}$ Osaka Medical Center and Research Institute for Maternal \\ and Child Health, Izumi 590-02, Japan
}

(Received February 2, 1988)

\begin{abstract}
Summary Nutritional status of vitamin E was assessed in very low birth weight infants of less than $1,500 \mathrm{~g}$, with respect to changes in plasma and red blood cell (RBC) tocopherol concentrations. The forty infants examined were divided into two groups in terms of their birth weight: group A, less than $1,000 \mathrm{~g}$; and group B, 1,000-1,500 g. Immediately after birth, plasma tocopherol level was $335 \pm 101 \mu \mathrm{g} / \mathrm{dl}$ in group $\mathrm{A}$ and $316 \pm 103 \mu \mathrm{g} / \mathrm{dl}$ in group B, while RBC tocopherol was $187 \pm 48 \mu \mathrm{g} / \mathrm{dl}$ and $231 \pm 72 \mu \mathrm{g} / \mathrm{dl}$ packed PBCs, in groups $\mathrm{A}$ and $\mathrm{B}$, respectively. In two infants, RBC tocopherol concentrations were less than $115 \mu \mathrm{g} / \mathrm{dl}$, this level being reported as the lowest of the normal range. After birth, plasma and RBC tocopherol levels decreased markedly during 4 to 6 weeks of life especially in group A, while no decrease below normal range was documented in RBC levels in group B. A fine granule preparation of tocopheryl nicotinate $(20 \mathrm{mg} / \mathrm{kg} /$ day $)$ was administered in seven other infants, three in group A and four in group B. All three infants in group A showed no elevation of plasma and $\mathrm{RBC}$ tocopherol levels during the first 4 or 5 weeks of the administration, but a marked elevation thereafter. In three of the four infants in group B, an elevation of plasma and RBC tocopherol concentrations was documented after 2 weeks of the administration. The above findings indicate that no deficiency exists even in very low birth weight infants immediately after birth, while the deficiency may develop after birth, due to a poor ability to absorb fat.
\end{abstract}

Key Words vitamin E, tocopherol, plasma, erythrocytes, neonate, lipid

As the assessment of human vitamin E status from a clinical standpoint has generally relied on serum or plasma tocopherol concentrations, it has been previously supposed that newborn infants are in a marginally vitamin E-deficient

${ }^{1}$ 田中裕久, 美濃 真, ${ }^{2}$ 竹内 徹 
state due to their low plasma tocopherol concentrations(1-3). However, estimations of nutritional vitamin $\mathrm{E}$ status based only on plasma levels are now recognized to be subject to error because the levels tend to fluctuate in relation to plasma lipids (4-6). Horwitt et al. (4) thus proposed plasma tocopherol expressed in terms of total lipids (tocopherol/lipid ratio) as a very reliable index of vitamin $\mathrm{E}$ status, and several clinical studies of the nutritional status of vitamin $\mathrm{E}$ have been undertaken, based on this index(4-6). Martinetz et al.(7) and Desai et al.(8) reported that this ratio in newborn infants appeared to be within an acceptable range (more than 0.8$)(4)$, indicating that the newborn infants may not be deficient in vitamin $\mathrm{E}$. On the basis of our findings on red blood cell (RBC) tocopherol, which is also thought to be an expression of vitamin E status (9-11), the majority of newborn infants showed a normal vitamin E status $(12,13)$. However, there is no precise information in very low birth weight infants, based on such new indices for the assessment of vitamin E status. Plasma tocopherol levels probably may underestimate nutritional status of vitamin $E$ in neonates. This report deals with vitamin $E$ status in very low birth weight infants. In addition, changes in plasma and $\mathrm{RBC}$ tocopherol levels were examined after oral administration of vitamin $\mathrm{E}$ to neonates, because a theoretical and experimental basis is being developed which advocates the use of parenteral tocopherol in pharmacological doses as a form of therapy to ameliorate or totally treat a variety of neonatal disorders (13-21), although some hazard and disappointing results have thus far been reported (22-25).

\section{MATERIALS AND METHODS}

Subjects. In the first study, forty newborn infants of very low birth weight were examined with respect to vitamin $E$ status in our newborn nursery, from November 1984 to May 1985. Characteristics for the infants examined are documented in Table 1. Eleven other infants born in the same period were excluded from this study, because six infants were severely ill and five infants died. The infants examined were divided into two groups based on the birth weight-less than $1,000 \mathrm{~g}$ (group A), and 1,000-1,500 g (group B).

In the second study, oral administration of a vitamin $\mathrm{E}$ preparation was undertaken after May 1985 in seven other premature infants. Their profiles are shown in Table 2. None of the infants who were selected randomly had respiratory problems or feeding trouble during the examination periods.

The compositions of the human milk and formula used in this study are listed in Table 3. All premature infants were first fed their own mother's milk by gastric gavage every $2 \mathrm{~h}$. Feedings were begun when the infant was stable (all within 1 week of birth) at a volume of $20-30 \mathrm{ml} / \mathrm{kg} /$ day, increased by a similar amount daily so that all infants achieved $180 \mathrm{ml} / \mathrm{kg} /$ day within 2 weeks, and maintained by daily adjustments according to weight increase. If the mother's milk was insufficient due to poor secretion, a formula (premature formula), listed in Table 3, was added until the infants' body weight reached $1,500 \mathrm{~g}$. After $1,500 \mathrm{~g}$ was attained, a formula 
Table 1. Characteristics for subjects without vitamin E supplementation.

\begin{tabular}{lcc}
\hline & \multicolumn{2}{c}{ Birth weight $(\mathrm{g})$} \\
\cline { 2 - 3 } & $500-999$ & $1,000-1,499$ \\
\hline Numbers & $14\left(2^{\mathrm{a}}\right)$ & $26\left(16^{\mathrm{b}}\right)$ \\
Male : Female & $6: 8$ & $13: 13$ \\
Inborn : Transport & $12: 2$ & $20: 6$ \\
Birth weight (g) & $855 \pm 83$ & $1,128 \pm 78^{\mathrm{c}}$ \\
Gestational age (weeks) & $27.2 \pm 1.3$ & $30.1 \pm 2.2$ \\
AGA:SGA & $11: 3$ & $21: 5$ \\
APGAR score 1 min $\quad 5$ min & $4.4 \pm 1.6$ & $5.5 \pm 2.5$ \\
& $7.1 \pm 1.3$ & $7.9 \pm 1.8$ \\
RDS $\quad 5$ & 6 \\
Intraventricular hemorrhage (IVH) & 3 & 3 \\
PDA & 5 & 3 \\
Chronic lung disease & 8 & $5.9 \pm 12.5$ \\
During oxygen therapy (days) & $37.4 \pm 35.5$ & $10.7 \pm 6.0$ \\
Days reached 120 kcal/kg/day & $30.6 \pm 16.8$ & \\
\hline
\end{tabular}

${ }^{\mathrm{a}} 500-749 \mathrm{~g} .{ }^{\mathrm{b}} 1,000-1,249 \mathrm{~g} .{ }^{\mathrm{c}}$ Mean \pm SD. ${ }^{\mathrm{d}}$ AGA, appropriate for gestational age; SGA, small for gestational age, less than 10 percentile by classification of Lubuchenco (43). ${ }^{e}$ IVH was diagnosed with echo and/or CT scanning.

Table 2. Characteristics of subjects with vitamin E supplementation.

\begin{tabular}{|c|c|c|c|c|c|c|c|}
\hline Infant & 1 & 2 & 3 & 4 & 5 & 6 & 7 \\
\hline Birth weight $(\mathrm{g})$ & 888 & 980 & 998 & 1,128 & 1,234 & 1,179 & 1,060 \\
\hline Gastational age (wks) & 25 & 28 & 28 & 29 & 30 & 29 & 33 \\
\hline Sex & $\mathrm{F}$ & $\mathbf{M}$ & $\mathrm{M}$ & $M$ & $\mathrm{~F}$ & $\mathrm{~F}$ & $\mathbf{M}$ \\
\hline APGAR score $1 \mathrm{~min}$ & 9 & 6 & 4 & 8 & 3 & 5 & 8 \\
\hline $5 \mathrm{~min}$ & 10 & 9 & 7 & 9 & 5 & 6 & 9 \\
\hline Growth & AGA & AGA & AGA & AGA & AGA & AGA & SGA \\
\hline
\end{tabular}

(regular formula) was used as an additional milk. An iron dosage of $6 \mathrm{mg} / \mathrm{day}$ was administered after 2 weeks of life. None of the infants had parenteral nutrition which contained tocopherol.

Gestational age was estimated by review of maternal records and confirmed by Dubowitz et al.'s examination(26).

Administration of vitamin $E$. The daily oral administration was undertaken after 2 weeks of life. The vitamin $\mathrm{E}$ used was a very fine granule preparation of $d l$ rac-alpha tocopheryl nicotinate (manufactured by Eisai Co., Ltd.) because of no increase in the osmolarity of the formula mixed preparation. The vitamin $\mathrm{E}$ preparation was suspended in a dosage of $10 \mathrm{mg} / \mathrm{kg}$ into the formula, which was

Vol. 34, No. 3, 1988 
Table 3. Composition of milks used in this study.

\begin{tabular}{lcccc}
\hline \multirow{2}{*}{ Milks } & Human milk & \multicolumn{2}{c}{ Formula } \\
\cline { 3 - 5 } & & & Premature & Regular \\
\hline Postpartum & $<1 \mathrm{wk}$ & $4-6 \mathrm{wks}$ & & \\
Sample numbers & 5 & 8 & 3 & 3 \\
Total lipids (mg/dl) & 2.00 & 2.01 & 2.18 & 3.60 \\
PUFA (\%) & 20 & 22 & 21 & 20 \\
Alpha-tocopherol (mg/dl) & 1.16 & 0.46 & 0.60 & 0.51 \\
Tocopherol/PUFA (mg/g) & 2.9 & 1.0 & 1.3 & 0.7 \\
\hline
\end{tabular}

The values represented are the mean values.

administered twice a day at 10:00a.m. and 10:00 p.m. Blood was drawn every week immediately prior to feeding with the vitamin E-fortified formula.

The study protocol was approved by the ethics committee at the college hospital, and the studies were performed after informed consent had been obtained from the parents.

Collection and preparation of blood samples. Blood was collected into heparinized tubes. Three $\mathrm{ml}$ of heparinized blood was centrifuged at $3,000 \mathrm{rpm}$ for $10 \mathrm{~min}$, and the RBCs were separated from plasma and washed with three $10 \mathrm{ml}$ portions of physiological saline. After the last washing, $0.6 \mathrm{ml}$ of the packed RBCs was resuspended into the same volume of normal saline, a part of which was used for the tocopherol assay, and the remainder for hematocrit determination.

Analyses. Plasma separated from RBCs was used for analysis of tocopherol. Tocopherol in plasma and the RBCs was analyzed by high performance liquid chromatography (HPLC) using modified Ishibashi et al.'s method (27), as described in a previous report (12). The values in RBCs obtained from HPLC analysis were corrected by hematocrit values in each sample. In this study, only values for alphatocopherol are given unless otherwise stated. Plasma total lipid was measured by sulfo-phospho-vanillin method (28).

Lipids were extracted by Bligh and Dyer's method (29) for milk analysis. Fatty acids of total lipids were interesterified into methyl esters with $3 \% \mathrm{HCl}$ in methanol $(97: 3, \mathrm{v} / \mathrm{v})$ under nitrogen gas at $85^{\circ} \mathrm{C}$ for $2 \mathrm{~h}(30)$ with added internal standard $(100 \mu \mathrm{g}$ of $n$-eicosanoic acid). The methyl esters were extracted with hexane, evaporated, and then dissolved in acetone to be analyzed using a gas liquid chromatography (GLC), (Shimadzu GC-7A) with a FID. A glass column $(3 \mathrm{~mm} \times 3.1 \mathrm{~m})$ packed with Shimalite (brown diatomite, $80-100 \mathrm{mesh}$, acid washed) as a support and containing 5\% Shinchrom E-71 (polyester nitrile; Shimadzu Co., Ltd.) was used. Student's $t$-test was used for statistical analysis. 


\section{RESULTS}

\section{Tocopherol levels in plasma and RBCs at birth}

With respect to blood samples collected during the first $24 \mathrm{~h}$ of life, plasma tocopherol levels were $335 \pm 101 \mu \mathrm{g} / \mathrm{dl}$ in group $\mathrm{A}$, and $316 \pm 103 \mu \mathrm{g} / \mathrm{dl}$ in group B. RBC tocopherol levels were $187 \pm 48 \mu \mathrm{g} / \mathrm{dl}$ in group $\mathrm{A}$ and $231 \pm 72 \mu \mathrm{g} / \mathrm{dl}$ in group B. The relationship between gestational age (weeks) and plasma tocopherol levels, and between gestational age and RBC tocopherol levels are shown in Table 4. The former showed no relationship, while the latter showed a slightly positive correlation $(r=0.40, p<0.05)$. A correlation was also observed between birth weight and $\mathrm{RBC}$ tocopherol levels $(r=0.35, p<0.05)$, but not between birth weight and plasma tocopherol levels. Two infants had RBC tocopherol concentrations of below $115 \mu \mathrm{g} / \mathrm{dl}$, this level being reported as the lowest of the normal range (12).

\section{Changes in tocopherol levels in plasma and RBCs after birth}

Figures 1 and 2 show changes in plasma and RBC levels after birth. In group $\mathrm{A}$, at 4 weeks of postnatal age the RBC levels became below the lowest normal range level $(115 \mu \mathrm{g} / \mathrm{dl})$, and then the low levels were maintained until 7 weeks of life. A remarkable increase was shown after 11 weeks of life. Plasma levels in group A immediately lowered after birth and reached the lowest level at 2 to 3 weeks of life. Plasma levels usually remained below the lowest normal level of $450 \mu \mathrm{g} / \mathrm{dl}$ throughout the periods examined. In group $\mathrm{B}, \mathrm{RBC}$ tocopherol levels were mostly maintained above $115 \mu \mathrm{g} / \mathrm{dl}$, although in this group the levels also lowered at 2 to 4 weeks of life. Plasma levels also usually remained below $450 \mu \mathrm{g} / \mathrm{dl}$. Since development of the absorption mechanism of the vitamin may relate to post-conceptional ages, we further examined tocopoherol changes in blood as a function of the gestational ages. When the groups were classified in terms of gestational age-less than 30 weeks $(28.0 \pm 1.7 \mathrm{wks}: \mathrm{M} \pm \mathrm{SD})$, and 30 or more weeks $(31.8 \pm 1.6$ wks: $\mathrm{M} \pm \mathrm{SD}$ ) - the plasma tocopherol was found to remarkably increase immediately after birth in the group of 30 or more gestational weeks, while in the less than 30 weeks group the level remained below $450 \mu \mathrm{g} / \mathrm{dl}$ for a long period (Figs. 3 and 4 ). In the group of longer gestation, RBC levels decreased until 2 weeks of life (cor-

Table 4. Correlation between gestational age or birth weight and blood tocopherol levels immediately after birth.

\begin{tabular}{cccc}
\hline Correlation & $n$ & $r$ & $p$ \\
\hline Gestational age $v s$. plasma & 35 & -0.05 & n.s. $^{\text {a }}$ \\
vs. RBC & 34 & 0.40 & $<0.05$ \\
Birth weight $v s$. plasma & 36 & -0.11 & n.s. \\
vs. RBC & 34 & 0.35 & $<0.05$ \\
\hline
\end{tabular}

${ }^{a}$ n.s., not significant.

Vol. 34, No. 3, 1988 


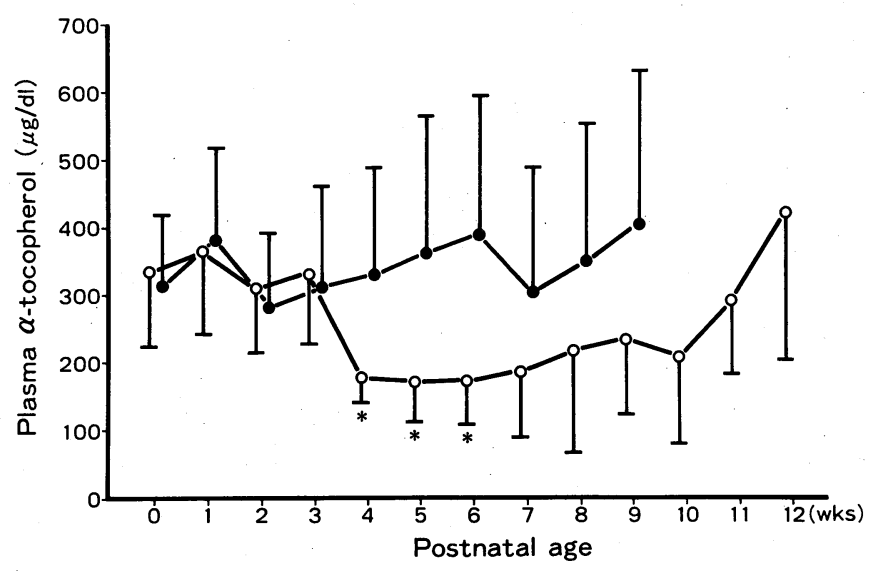

Fig. 1. Changes in plasma tocopherol in very low birth weight infants after birth in terms of birth weight. The values are represented as the mean \pm SD. Open circles show the values in group A (less than $1,000 \mathrm{~g}$ birth weight), and closed circles show those in group B $(1,000-1,500 \mathrm{~g})$. ${ }^{*}$ Significant difference $(p<0.001)$.

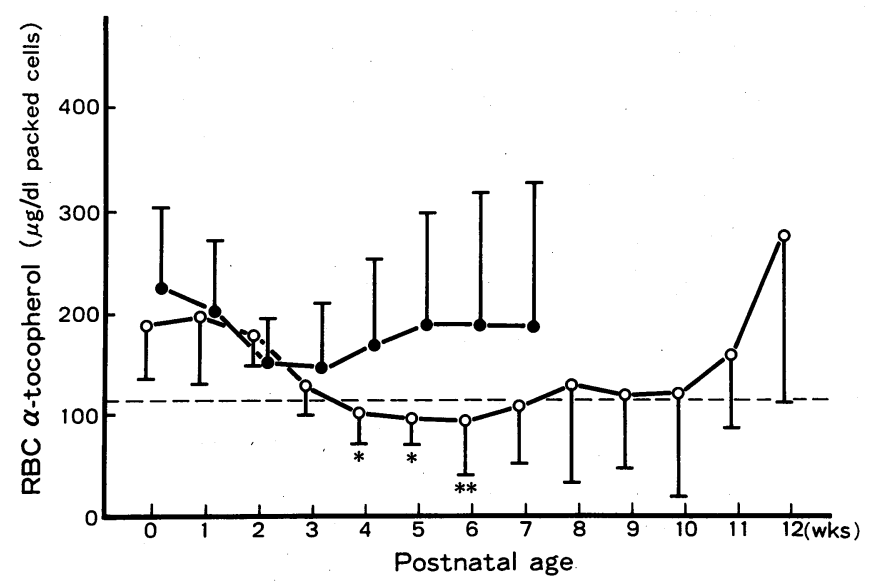

Fig. 2. Changes in RBC tocopherol in very low birth weight infants after birth in terms of birth weight. The values are represented as the mean \pm SD. Open and closed circles are the same as those in Fig. 1. * Significant difference $(p<0.001)$, $* *(p<0.002)$.

responding to 32 weeks of post-conceptional age), and thereafter there was a rise which coincided with that of the plasma level. On the other hand, in the group of shorter gestation the plasma and RBC tocopherol levels decreased and remained still at the lowest level at 11 weeks of life. 


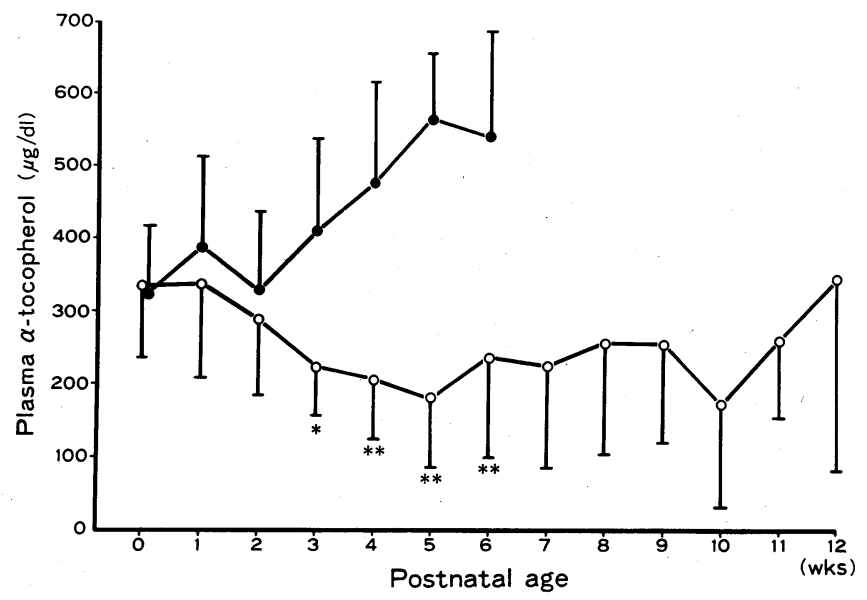

Fig. 3. Changes in plasma tocopherol in very low birth weight infants after birth in terms of gestational age. The values are represented as the mean \pm SD. Open circles show the values in the group of less than 30 weeks gestation $(28.0 \pm 1.7$ wks: $\mathrm{M} \pm \mathrm{SD}$ ) and closed circles show those in another group of 30 or more weeks $(31.8 \pm 1.6$ wks: $\mathrm{M} \pm \mathrm{SD})$. ${ }^{*}$ Significant difference $(p<0.001),{ }^{* *}(p<0.005)$.

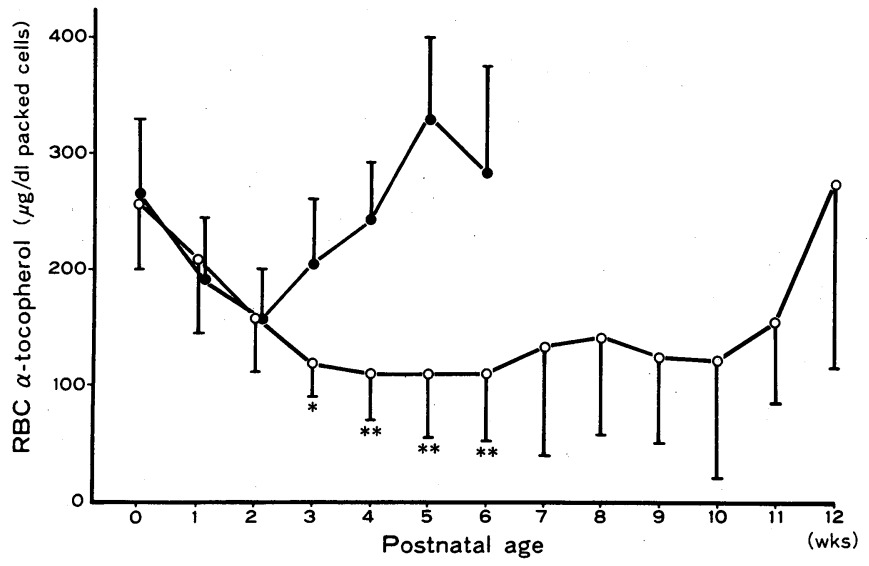

Fig. 4. Changes in RBC tocopherol in very low birth weight infants after birth in terms of gestational age. The values are represented as the mean \pm SD. Open and closed circles are the same as those in Fig. 3. *Significant difference $(p<0.001)$, $* *(p<0.002)$.

\section{Administration with vitamin E preparation}

Changes in plasma and RBC tocopherol levels were examined in seven infants, as shown in Figs. 5 and 6. The three infants corresponding to group A showed no elevation of their plasma and RBC tocopherol levels during the first 4 or 5 weeks of the administration. However, this was followed by a prompt and marked elevation 


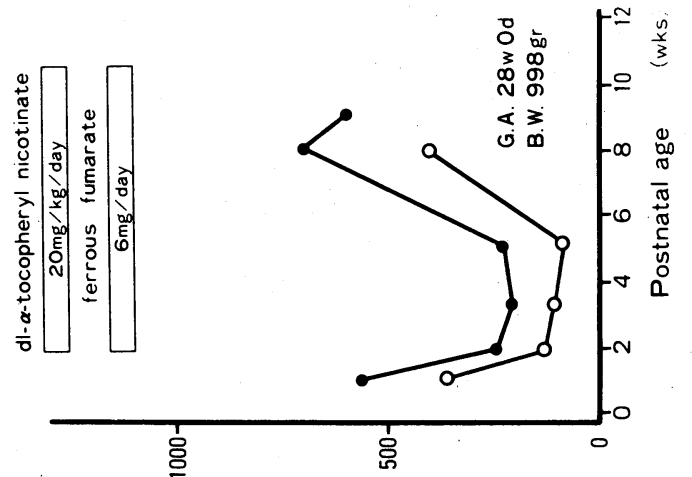

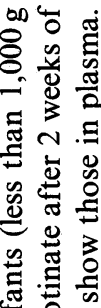

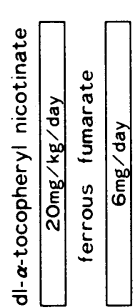

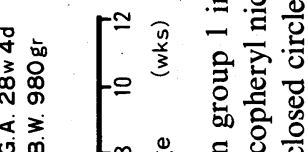

I 8 은

赵 웅 ชิ 응. ‥

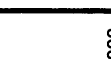

官

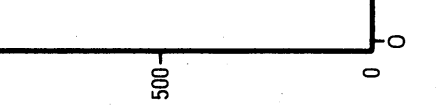

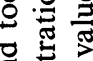

ర్త

ช.

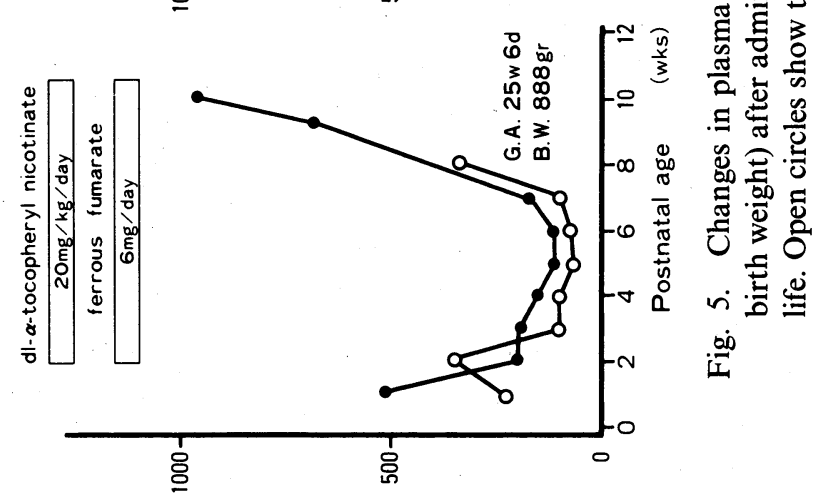

jOsaydosol-D

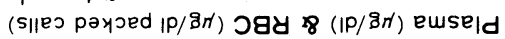




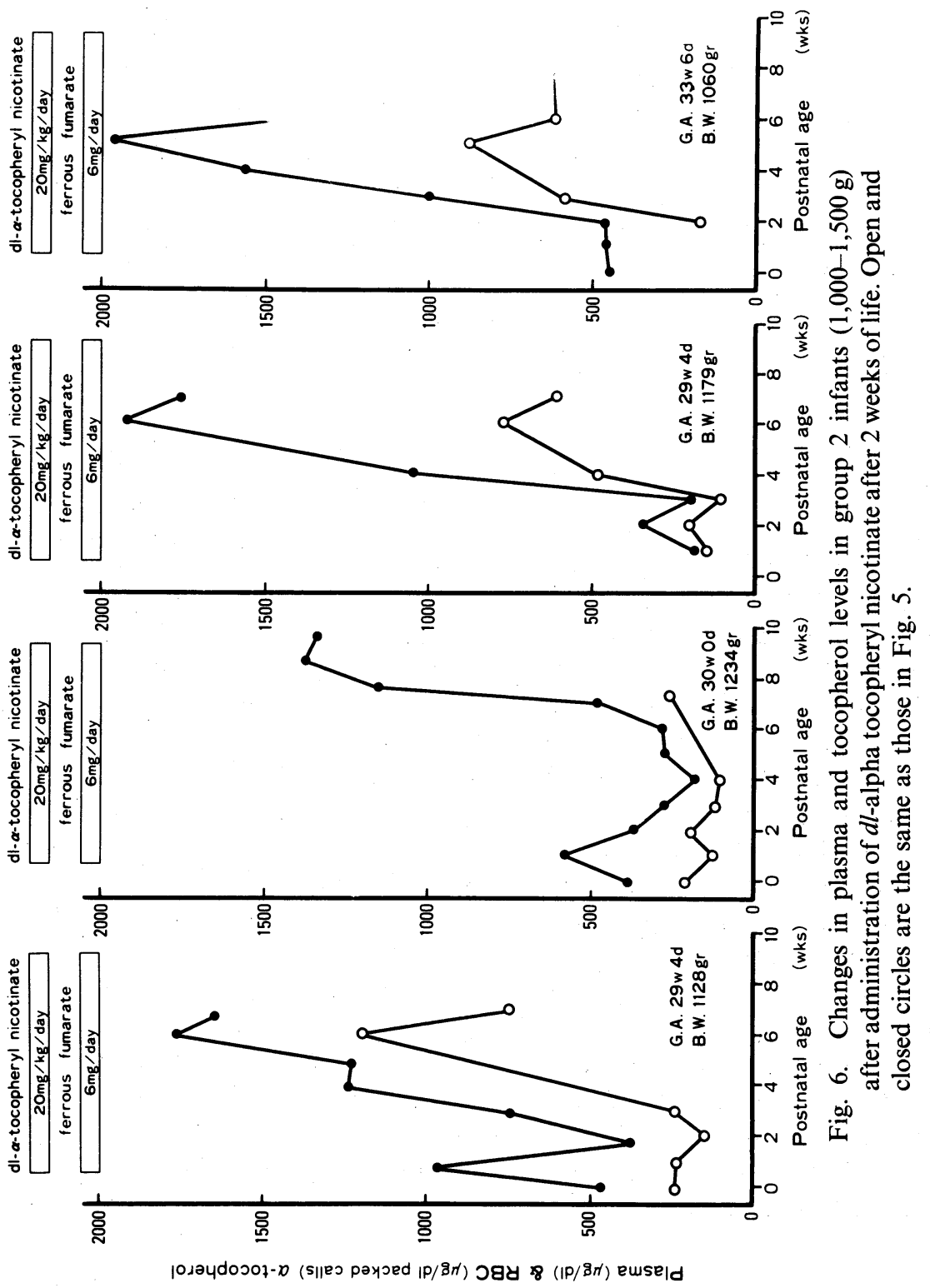

Vol. 34, No. 3, 1988 


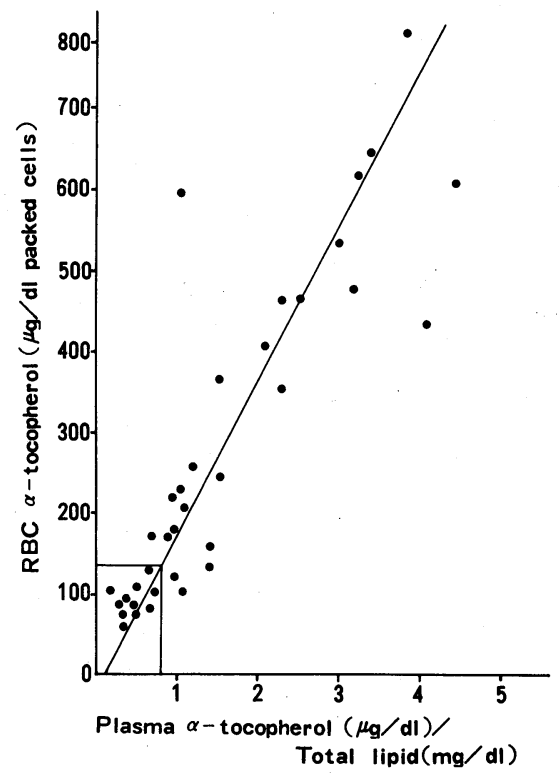

Fig. 7. Correlation between $\mathrm{RBC}$ tocopherol and plasma tocopherol/total lipid $(p<0.001, r=0.88, n=36)$.

in both plasma and RBC levels during 6 to 8 weeks of life. Among the four infants corresponding to group $\mathrm{B}$, an elevation of plasma and RBC tocopherol concentrations was documented in three infants after 2 weeks of the administration, whereas in the fourth infant, no elevation was shown until 8 weeks of life, as in group A. In all of the infants, changes in $\mathrm{RBC}$ tocopherol levels were almost parallel with those in plasma levels. After the tocopheryl nicotinate administration in a dosage of $20 \mathrm{mg} / \mathrm{kg} /$ day, the elevated maximum plasma levels were within usual adult levels (less than 2,000 $\mu \mathrm{g} / \mathrm{dl}$ ), while the maximum $\mathrm{RBC}$ tocopherol levels reached levels higher than the upper normal level $(320 \mu \mathrm{g} / \mathrm{dl})(12)$ in three of the four infants in group B.

4. Correlation between RBC tocopherol and plasma tocopherol/total lipid ratios

Correlation of RBC tocopherol levels to the tocopherol/lipid ratios was examined only in limited cases of the premature infants. Total lipids were distributed from 233 to $636 \mathrm{mg} / \mathrm{dl}(381 \pm 92 \mathrm{mg} / \mathrm{dl}: \mathrm{M} \pm \mathrm{SD})$ in the infants, within 2 months of life. As shown in Fig. 7, RBC tocopherol levels were very closely correlated with the ratios $(r=0.88, p<0.001, n=36)$.

\section{DISCUSSION}

In classical investigations, it has been believed that newborn and premature infants are marginally deficient in vitamin $\mathrm{E}$, because of their low plasma tocopherol 
levels and the increased susceptibility of their RBCs to hydrogen peroxide stress. In addition, this assumption also comes from the finding that the transportation of tocopherol from mother to fetus may be impaired, given that plasma tocopherol concentrations in cord blood are extremely low, as compared with those in the mother $(31,32)$. However, it is well known that plasma tocopherol levels closely related to plasma total lipids(4-6), while the hydrogen hemolysis test lacks specificity and reproducibility (33,34). Martinetz et al.(7) and Desai et al(8) reported that low plasma tocopherol concentrations in neonates were due to a low plasma lipid level, rather than a true deficiency of vitamin E. The tocopherol/lipid ratios, proposed by Horwitt et al. (4) as an expression which represents the most reliable index routinely available in humans, have not yet been precisely investigated in the low birth weight infants. Thus, vitamin E status in neonates has not yet been clearly established. Although our previous study reported a close correlation between the tocopherol/total lipid ratios and RBC tocopherol concentration in a population survey in Japanese children (12), it was also confirmed again in the very low birth weight infants in this study (Fig. 7). We have previously further confirmed that $\mathrm{RBC}$ tocopherol concentrations reflect tocopherol concentrations in liver tissues, especially the concentrations in the subcellular fractions, as the nutritional status of vitamin $\mathrm{E}$ varies in rats $(11,35)$. From this study of vitamin $\mathrm{E}$ status based on $\mathrm{RBC}$ tocopherol in very low birth weight premature infants, it appeared that even in such infants, no vitamin $\mathrm{E}$ deficiency exists immediately after birth, because the $\mathrm{RBC}$ tocopherol concentrations were proportional to the normal values, which have previously been reported as $176 \pm 9 \mu \mathrm{g} / \mathrm{dl}(\mathrm{M} \pm \mathrm{SEM}$, ranging from 101 to $243 \mu \mathrm{g} / \mathrm{dl})(12)$. If there is no vitamin E deficiency in very low birth weight infants at birth, the mechanism for tocopherol transportation from mother to fetus remains to be elucidated. Tanaka and Mino (36) recently reported on the possibility of cell-tocell transfer to tocopherol other than through the lipoproteins transportation. Therefore, such a mechanism may play a role in transportation through the placenta. In the very low birth weight infants with less than $1,000 \mathrm{~g}$ (group A), the plasma and RBC tocopherol concentrations, however, gradually decreased during the neonatal period after birth, as compared with the infants weighing $1,000-1,500 \mathrm{~g}$ (group B), even though daily tocopherol intake remained with an adequate tocopherol/PUFA ratio after birth, as shown in Table 3. Such a result could be attributable to a poor ability to absorb lipids (including vitamin E) in milk. This hypothesis was supported by the subsequently observed changes in plasma and RBC tocopherol concentrations after administration with tocopheryl nicotinate, as shown in Fig. 5. Despite the intake of a large amount of a vitamin E preparation, no increase in tocopherol in plasma and RBCs was observed during the first 4 to 5 weeks of administration (corresponding to 6-7 weeks of life and 31-32 weeks of post-conceptional age), indicating a poor absorption of vitamin $\mathrm{E}$, especially in the infants of less than $1,000 \mathrm{~g}$ birth weight. However, a prompt increase in plasma and RBC tocopherol concentrations at 32-35 weeks of post-conceptional ages, indicated that the absorption mechanism had developed. There have been conflicting 
reports (37-39) suggesting that orally administered tocopherol could be absorbed in very low birth weight infants. However, it is difficult to compare the available data because infants were of various birth weights, and may have received different tocopherol preparations. In our study, plasma tocopherol levels changed within a deficient range of below $500 \mu \mathrm{g} / \mathrm{dl}(40)$. Since $\mathrm{RBC}$ tocopherol concentration is known to be almost constant regardless of age(12), a finding that the RBC tocopherol concentrations in the very low birth weight infants decreased below the lowest limit of normal range, seems to indicate that vitamin $\mathrm{E}$ deficiency developed in this period. The infants with more than $1,000 \mathrm{~g}$ birth weight (group B), on the other hand, showed no reduction of RBC tocopherol concentrations below normal range during the respective periods, indicating the development of a normal absorption mechanism for maintaining vitamin $\mathrm{E}$ status. Thus, for the nursing of premature infants, the risk of vitamin E deficiency should still be considered, especially in very low birth weight infants, until their fat absorption mechanism develops.

It is well known that dietary vitamin $\mathrm{E}$ requirement (which usually directly reflects dietary fatty acids) increases a PUFA composition increases in situ $(41,42)$. In this study, PUFA composition and lipid content were examined in eight randomly stocked breast milk samples. Colostrum in preterm mothers did not significantly differ from their mature milk, with regard to lipid content and PUFA composition, while tocopherol content in colostrum was higher than in the mature milk. A formula for premature infants had similar constituents regarding lipid content and PUFA composition, and thus did not significantly differ from those in a regular formula. Therefore, tocopherol changes observed in the infants in this study may not be due to different milk series.

In the second investigation of vitamin $\mathrm{E}$ administration, the elevated RBC tocopherol levels were much higher than those assumed on the basis of plasma levels, after the absorption mechanism developed. A large amount of tocopherol in RBCs found in this study is probably due to a low level of plasma lipoproteins. Similar transportation is thus expected to occur in tissues, as assumed in our previous reports $(11,34)$. Recently, several reports (22-25) have warned of vitamin E toxicity including an increased incidence of necrotizing enterocolitis (NEC) and sepsis in low birth weight infants who received pharmacological doses of vitamin $\mathrm{E}$ preparation as a therapy for retrolental fibroplasia (RLF)(22-25). In these risk cases, plasma tocopherol concentrations were reported to exceed $3.5 \mathrm{mg} / \mathrm{dl}(21)$. The level of $3.5 \mathrm{mg} / \mathrm{dl}$ has been thought to be within the adult physiological range in these reports. In our present study on changes in RBC tocopherol after administration, $\mathrm{RBC}$ tocopherol concentrations markedly exceeded the adult physiological range (12), even though plasma tocopherol concentrations were within $2 \mathrm{mg} / \mathrm{dl}$. This finding suggests that the tocopherol concentration must elevate to extremely unusual concentrations at the effective sites of biomembrane, as plasma tocopherol exceeds $3.5 \mathrm{mg} / \mathrm{dl}$. This may cause unpredictable effects in premature infants. Therefore, the risks in administering large dosages of tocopherol preparations 
should be carefully considered in such newborn infants, even if their plasma tocopherol concentrations do not exceed the adult physiological level.

A Grant-Aid (61480225) for Scientific Research from the Ministry of Education, Science, and Culture, Japan, and a Grant for Maternal and Child Health Research from the Ministry of Health and Welfare, Japan.

\section{REFERENCES}

1) Lo, S. S., and Hitzig, W. H. (1973): Vitamin E and haemolitic anemia in premature infants. Arch. Dis. Child., 48, 360-365.

2) Graeber, J. E., Williams, M. L., and Oski, F. A. (1977): The use of intramuscular vitamin $\mathrm{E}$ in the premature infants. J. Pediatr., 90, 282-284.

3) Farrell, P. M. (1979): Vitamin E deficiency in premature infants. J. Pediatr., 95, 869872.

4) Horwitt, M. K., Harvey, C. C., Dahn, C. C., Jr., and Scary, M. T. (1972): Relationship between tocopherol and serum lipid levels for determination of nutritional adequacy. Ann. N. Y. Acad. Sci., 203, 233-236.

5) Haga, P., and Kran, S. (1981): Plasma vitamin E levels and vitamin E/beta-lipoprotein relationship in small premature infants during the early anemia of prematurity. Eur. $J$. Pediatr., 136, 143-147.

6) Farrell, P. M., Mischer, E. H., and Gutcher, G. R. (1982): Evaluation of vitamin E deficiency is children with lung disease. Ann. N. Y. Acad. Sci., 393, 96-108.

7) Martinetz, P. E., Concalves, A. L., Jorge, S. M., and Desai, I. D. (1981): Vitamin E, placental blood and its relationship to maternal and newborn level of vitamin E. $J$. Pediatr., 99, 298-300.

8) Desai, I. D., Swann, M. A., Garcia Traveres, M. L., Dutra de Oliveria, B. S., Pharm, B., and Duarte de Oliveria, J. E. (1980): Vitamin E status of agricultural migrant workers in Southern Brazil. Am. J. Clin. Nutr., 33, 2669-2673.

9) Mino, M., Nishida, Y., Kijima, Y., Iwakoshi, M., and Nakagawa, S. (1979): Tocopherol level in human blood cells. J. Nutr. Sci. Vitaminol., 25, 505-516.

10) Mino, M., Nakagawa, S., Tamai, H., and Miki, M. (1982): Clinical evaluation of red blood cell tocopherol. Ann. N. Y. Acad. Sci., 393, 175-178.

11) Mino, M., Kasugai, O., and Nagita, A. (1985): Relationship between red blood cell and liver tocopherol concentration after administration and depletion of vitamin E. Int. J. Vitam. Nutr. Res., 55, 47-51.

12) Mino, M., Kitagawa, M., and Nakagawa, S. (1985): Red blood cell tocopherol concentration in a normal population of Japanese children and premature infants in relation to assessment of vitamin E status. Am. J. Clin. Nutr., 41, 631-638.

13) Johnson, L. H., Schaffer, D., and Boggs, T. R. G. (1974): The premature infant, vitamin E deficiency and retrolental fibroplasia. Am. J. Clin. Nutr., 27, 1158-1173.

14) Johnson, L. H., Schaffer, D. B., Rubinstein, D., Crawford, C. S., and Boggs, T. R. (1976): The role of vitamin E in retrolental fibroplasia. Pediatr. Res., 10, 425 (Abstract).

15) Finer, N. N., Schindler, R. F., Grant, G., Hill, G. B., and Peters, K. L. (1982): Effect of intramuscular vitamin $\mathrm{E}$ on frequency and severity of retrolental fibroplasia: a controlled trial. Lancet, I, 1087-1089.

16) Ehrenkranz, R., Bonta, B. W., Ablow, R. C., and Warshow, J. B. (1978): Amelioration 
of bronchopulmonary dysplasia after vitamin $\mathrm{E}$ administration: a preliminary report. New Engl. J. Med., 299, 564-569.

17) Saldanha, R. L., Cepeda, E. E., and Porand, R. L. (1982): The effect of vitamin E prophylaxis on the incidence and severity of bronchopulmonary dysplasia. J. Pediatr., 101, 89-93.

18) Chiswick, L., Wynn, J., and Toner, N. (1982): Vitamin E and intraventricular hemorrhage in the newborn. Ann. N. Y. Acad. Sci., 393, 109-120.

19) Puklin, J. E., Simon, R. M., and Ehrenkranz, R. A. (1982): Influence on retrolental fibroplasia of intramuscular vitamin $\mathrm{E}$ administration during respiratory distress syndrome. Ophthalmology, 89, 96-103.

20) Finer, N. N., Schindler, R. F., Peter, K. L., and Grant, G. D. (1983): Vitamin E and retrolental fibroplasia, improved visual outcome with early vitamin E. Ophthalmology, 90, 428-435.

21) Hittner, H. M., Speer, M. E., Rudolph, A. J., Cindy Blifeld, Prebhujeet Chadda, Blair Holblein, M. E., Godio, L. B., and Kretzer, F. L. (1984): Retrolental fibroplasia and vitamin $\mathrm{E}$ in the preterm infant-Comparison of oral versus intramuscular: Oral administration. Pediatrics, 73, 238-249.

22) Finer, N. N., Peters, K. L., Heyek, Z., and Merkel, C. L. (1984): Vitamin E necrotizing enterocolitis. Pediatrics, 73, 387-393.

23) Lorsch, V., Murphy, D., Hoersten, L. R., Harris, E., Fitzgerald, J., and Sinha, S. N. (1985): Unusual syndrome among premature infants: Association with a new intravenous vitamin E product. Pediatrics, 75, 598-602.

24) Johnson, L., Bowen, F. W., Abbasi, S., Herrman, N., Weston, M., Sacks, L., Porat, R., Stahl, G., Peckham, G., Delivoria-Papadopoulus, M., Quinn, G., and Schaffer, G. (1985): Relationship of prolonged pharmacologic serum level of vitamin $E$ to incidence of sepsis and necrotizing enterocolitis in infants with birth weight 1,500 gram or less. Pediatrics, 75, 619-638.

25) Committee on Fetus and Newborn (1985): Vitamin E and the prevention of retinopathy of prematurity. Pediatrics, 75, 315-316.

26) Dubowitz, L. M., Dubowitz, V., and Goldberg, C. (1970): Clinical assessment of gestational age in the newborn infants. J. Pediatr., 77, 1-10.

27) Ishibashi, K., Abe, K., Ohmae, M., Kawabe, Y., and Katsui, G. (1977): Determination of tocopherols in red blood cells by high speed liquid chromatography. Vitamins (J. Vitamin Soc. Jpn.), 51, 415-422.

28) Frings, C. S., and Dunn, R. T. (1970): A colorimetric method for determination of total serum lipids based on the sulfo-phospho-vanillin reaction. Am. J. Clin. Pathol., 53, 89-91.

29) Bligh, E. G., and Dyer, W. J. (1959): A rapid method of total lipid extraction and purification. Can. J. Biochem. Physiol., 37, 911-917.

30) Tamai, H., Miki, M., and Mino, M. (1986): Hemolysis and membrane lipid changes induced by xanthine oxidase in vitamin E deficient red cells. J. Free Radicals Biol. Med., $2,49-56$.

31) Leonard, P. J., Doyle, E., and Harrington, W. (1972): Levels of vitamin E in the plasma of newborn infants and of the mother. Am. J. Clin. Nutr., 25, 480-484.

32) Mino, M., and Nishino, H. (1973): Fetal and maternal relationship in serum vitamin $E$ level. J. Nutr. Sci. Vitaminol., 19, 475-482.

33) Horwitt, M. K., Harvey, C. C., and Harmon, E. M. (1968): Lipid, alpha-tocopherol, and erythrocyte hemolysis. Vitam. Horm., 26, 487-499. 
34) Mino, M., Nishida, Y., Murata, K., Takegawa, M., Katsui, G., and Yuguchi, Y. (1978): Studies on the factors influencing the hydrogen peroxide hemolysis test. J. Nutr. Sci. Vitaminol., 24, 383-395.

35) Mino, M., Kasugai, O., and Shimizu, T. (1985): Red blood cell tocopherol and liver tocopherol in hyperlipemic rats as compared with plasma tocopherol. Lipids, 20, 488491.

36) Tanaka, H., and Mino, M. (1986): Membrane-to-membrane transfer of tocopherol in red blood cells. J. Nutr. Sci. Vitaminol., 32, 463-474.

37) Bell, E. F., and Filer, L. J. (1981): The role of vitamin $\mathrm{E}$ in nutrition of premature infants. Am. J. Clin. Nutr., 34, 414-422.

38) Jansson, L., Lindroth, M., and Tyoeppoenen, J. (1984): Intestinal absorption of vitamin E in low birth weight infants. Acta Paediatr. Scand., 73, 329-332.

39) Neal, P. R., Erickson, P., Baenziger, J. C., Olson, J., and Lemons, J. A. (1986): Serum vitamin $\mathrm{E}$ levels in the very low birth weight infants during oral supplementation. Pediatrics, 77, 636-640.

40) Horwitt, M. K. (1962): Interrelationship between vitamin $E$ and polyunsaturated fatty acids in adult men. Horm. Vitam., 20, 541-558.

41) Ciccoli, L., Hayek, Y., Berti, D., and Bracci, R. (1981): Fatty acid pattern of the erythrocyte lipids and plasma vitamin E in the first days of life. Biol. Neonate, 40, 187195.

42) Gross, S. J., and Gabriel, E. (1985): Vitamin E status in premature infants fed human milk or infant formula. J. Pediatr., 106, 635-638.

43) Lubuchenco, L. O., Hansman, C., Boyd, E., and Dressler, M. (1963): Intrauterine growth as estimated from live-born birth weight data at 24 to 42 weeks of gestation. Pediatrics, 32, 793-800. 